\title{
PAISAJES DEL EXILIO EN LA POESÍA DE JUAN BALBOA BONEKE: COMPROMISO SOCIAL CON LA PATRIA GUINEOECUATORIANA ${ }^{1}$
}

\author{
POR \\ Dosinda GarcíA-Alvite \\ Denison University
}

Como indica el crítico y autor Paul Tiyambe Zeleza, entre los temas literarios tratados por escritores africanos, el del exilio es uno de los más destacados (2). Como un proceso material, requiere un movimiento transnacional de un estado-nación estado a otro, como consecuencia de presiones y/o persecuciones políticas, económicas, religiosas, culturales, sociales e incluso sexuales. Este cambio vital se caracteriza por los sentimientos de dolor y pérdida, y se manifiesta a través de alienación cultural, de opresión política e incluso de los conflictos derivados de una posible afiliación cosmopolita.

En el caso de Guinea Ecuatorial la experiencia del exilio tiene una larga tradición y ha afectado a este país y sus ciudadanos en múltiples áreas. Específicamente, en el ámbito literario se han visto las consecuencias del exilio en tres niveles: por un lado, la mayoría de los escritores de esta nación lo han experimentado personalmente, por otro, el exilio se ha constituido en un tema central del corpus literario nacional producido hasta el momento, y finalmente, la experiencia exílica origina acercamientos alternativos a la historia nacional hegemónica, facilitando una perspectiva contrapuntal de ésta. Por ejemplo, las novelas de Joaquín Mbomío Bacheng Huellas bajo la tierra y El párroco de Niefang, y la de Donato Ndongo Los poderes de la tempestad, se enfocan directamente en los procesos de diáspora provocados por la dictadura Mací́sta. A su vez, el ensayo La condición humana de Eugenio Nkogo Ondo y múltiples poemas de Ciríaco Bokesa, Francisco Zamora Loboch, Anacleto Oló Mibuy, Cristino Bueriberi Bokesa y otros, examinan la dramática experiencia de la separación física, social y cultural del sujeto alejado de su patria provocados por el nguemismo. Diferentes aspectos de la representación de la experiencia exílica de autores guineoecuatorianos han sido ya examinados por varios críticos. ${ }^{2}$

1 Este ensayo fue presentado en una versión abreviada en la conferencia sobre Guinea Ecuatorial celebrada en la Universidad de Hofstra en abril 2009, titulada "Between Three Continents."

2 Donato Ndongo comenta en su antología sobre la importancia de la temática exílica en la litertura de Guinea Ecuatorial: "La obsesión de la literatura guineana"-sobre todo de la poesía-está, por el contrario, 
Menos atención se ha dedicado, sin embargo, a la poesía de Juan Balboa Boneke (1938-2014), considerado uno de los escritores más prolíficos dentro del panorama de literatura guineoecuatorial ya que su corpus literario incluye narración, ensayos y poesía, siendo éste el género en el que afirma encontrarse más realizado. ${ }^{3}$ Sus composiciones poéticas merecen un estudio en detalle porque exploran de modo recurrente y complejo el papel que el exilio, la dispersión y fragmentación social y personal producen en la configuración de la nación africana recientemente independizada al mismo tiempo que, ejerciendo un profundo compromiso social, ofrece una visión idealista de reconstrucción de la identidad nacional. En esta línea, el autor y crítico literario más reconocido de Guinea Ecuatorial, Donato Ndongo afirma que Juan Balboa Boneke "siente antes que nada [...] Como los gritos de su pueblo bohobé, su motivo no es la belleza por la belleza, sino expresar, dejar constancia de sus alegrías y sus tristezas. Y ahí está Juan Balboa Boneke paseando su humanidad por el mundo, buscando la justicia, la paz y la libertad a la vuelta de cada esquina" (Antología 49). Reafirmando esta evaluación M'bare N'gom informa que "El exilio no sólo es un tema recurrente en la obra de Juan Balboa Boneke, sino también una vivencia cotidiana [...] Esa presencia obsesiva del exilio en la obra de Juan Balboa Boneke expresa, además, la angustia del desarraigo, la falta de comunicación interpersonal y la crisis de identidad" ("Introducción” 23).

Efectivamente, la trayectoria vital de Juan Balboa Boneke se halla definida por momentos trascendentales de la historia de Guinea Ecuatorial como nación recientemente independizada. Nacido en 1938 en Rebola, en la isla de Bioko, y educado como maestro en Malabo y como trabajador social en Granada, su vida se halla jalonada por dos extensos periodos de exilio (durante la dictadura de Macías y a partir de 1994 hasta la actualidad). Obras poéticas como O Boriba (el exiliado) (1982); Susurros y pensamientos: desde mi vidriera (1983); Sueños en mi selva. Antología poética (1987); Sueños de mi selva (1987); Las brumas de mi jardín y Requiebros (1994); presentan el exilio como una condición existencial y epistemológica, mostrando los contextos materiales y metafóricos en los que se desarrolla. La visión que predomina es una en la que el exilio es una soledad debilitante, una sequía, un estado de ser y estar discontinuo. En este sentido, su obra refleja las experiencias y sentimientos de toda una generación de guineoecuatorianos, a los que él denominó "la generación perdida", que vivió lo que Donato Ndongo clasificó como "los años del silencio" y Ciríaco Bokesa llamó "la época del mutis", de modo que las únicas manifestaciones literarias de Guinea Ecuatorial durante aquel periodo

en el dilatado periodo de la dictadura de Macias", y señala dos elementos que aparecen nítidos desde un principio: "el tremendo trauma que ha supuesto para el país y sus habitantes, y la nostalgia que suscitó el exilio" (Antología 10 y 29). De modo similar, N'gom indica que, "[E]l exilio, como experiencia precaria y traumática, ocupa un lugar destacado en la formulación del discurso alternativo" ("Introducción" 23). Benita Sampedro examina este tema en varias composiciones poéticas.

Véase la entrevista realizada por M'bare N'gom en Diálogos con Guinea (91 a 100).

Revista Iberoamericana, Vol. LXXX, Núms. 248-249, Julio-Diciembre 2014, 813-833 ISSN 0034-9631 (Impreso) 
-la década de 1969 a 1979- se produjeron en el exilio. De hecho, la obra de Balboa Boneke se distingue por presentar en su poesía tres líneas de concentración temática que son constantes en la literatura producida sobre y en el exilio de Guinea Ecuatorial, y que continúan vigentes en el presente. ${ }^{4}$ Primero, muchos de los escritores que fueron al exilio no han podido regresar permanentemente a Guinea, por lo que la experiencia exílica se halla fuertemente teñida de nostalgia y añoranza por un territorio y modos de pertenencia nacional perdidos o en peligro; segundo, el proyecto de nación africana independiente fue frustrado por la dictadura de Macías tras la independencia, y continúa secuestrado por el gobierno de Obiang, haciendo que el nguemismo haya retrasado y hasta suprimido el desarrollo nacional esperado por todos sus ciudadanos, lo que motiva visiones nacionales alternativas de Guinea Ecuatorial; tercero, en respuesta a esta situación, la poesía de Juan Balboa Boneke se erige como un ejemplo insigne del tipo de corpus desarrollado por ciertos intelectuales africanos a los que el escritor y crítico Nesbitt denomina "exiliados progresivos", para quienes la condición exílica ha acentuado el proceso de compromiso social que establecen con su país.

\section{Nostalgia de Guinea Ecuatorial y COMPROMiso exílico}

La reflexión sobre la devastadora dislocación personal y psicológica que afecta la capacidad de acción del exiliado, hasta que parece imposible actuar para transformar la situación opresora de su país, se muestra en una multitud de poemas de Balboa Boneke. Composiciones como "Quiero regresar a mi hogar", "Largo el camino", "Volveré", "Deseo de libertad", "Nostalgia rebolana", "Frustración y esperanza" y "Otras voces en el silencio" muestran una visión exílica desesperada y esperanzada a la vez. Estos poemas que recuerdan, recrean y reimaginan el espacio físico y la comunidad espiritual que el autor evoca como Guinea Ecuatorial tocan dos temas principales en la clasificación que se propone aquí: por un lado, la nostalgia por el espacio geográfico nacional con el que la voz poética se identifica, y por otro, la redefinición de la escritura exílica como un ejercicio socialmente comprometido.

El tema de lo que el propio Balboa Boneke denomina "la orfandad de la tierra" (N'gom, "Memoria" 105) se caracteriza por una evocación ensoñadora de Guinea Ecuatorial, que desde el exilio se vive como un lugar prohibido y remoto. El espacio geográfico, físico del estado-nación se carga de significados relacionales adquiriendo connotaciones personales. Los poemas describen las montañas, colinas y paisajes, que

${ }^{4}$ Las diferentes calificaciones atribuidas al exilio por Balboa Boneke, Donato Ndongo y Ciríaco Bokesa provienen de los propios autores en sus entrevistas con el profesor M'bare N'gom Faye, publicadas en Diálogos con Guinea $(96-7,104)$. La obra de este autor presenta ejemplos de escritura exílica con características comunes a las de casi todas las naciones-estado africanas que sufrieron el exilio de sus ciudadanos en el período post-independendista.

Revista Iberoamericana, Vol. LXXX, Núms. 248-249, Julio-Diciembre 2014, 813-833 
el poeta rememora y explora mentalmente mientras expone su alejamiento de ellos. La mayoría de estas creaciones idealizan la geografía guineana evocando sus playas, ríos, campos, su vegetación específica y el clima, todos aspectos reconocidos por muchos guineanos desplazados y con los que pueden identificarse inmediatamente. Por ejemplo en el poema "Nostalgia" los versos que dicen: "Playa de Boloko/ playa/ de Negritud,/ desde mi exilio/ añoro tu calor;/ tu fragante aroma/ quiero percibir/ y a la calidez de tu regazo/ deseo retornar", son ejemplares del tipo de expresión nostálgica que se refiere a un paisaje campestre, pastoral, idílico que puede considerarse el paraíso abandonado al que hay que regresar. ${ }^{5}$ De modo similar a otros poetas que ensalzan sus conexiones con la tierra, ésta parece convertirse en un medio gnóstico de la identidad propia y la de la comunidad porque "without the land, there is no real self-knowledge" (Munro 35).

Más específicamente, en los poemarios de Balboa Boneke se presenta un contraste entre dos tipos de paisajes: el rural y el urbano, con un yo lírico que se identifica de modo preferente con el ámbito campestre que aparece como el repositorio de autenticidad, paz y tranquilidad. En Requiebros, composiciones como "Identidad" ( 43), "Diálogo" (50), "La seca" (51), "La siembra" (53) ofrecen una voz poética que busca ser comparada a un labrador que cultiva la tierra y siente que cumple con su destino al obtener frutos de ella. El paisaje rural, incluso rústico - poco manipulado por otros humanos-aparece en sus obras como un modo de resarcirse de su dolorosa experiencia, llegando al extremo de que a veces el hablante parece querer controlar mentalmente esta tierra, en lugar de permitirle que siga su curso natural, para compensar por su sufrimiento o agonía. La imagen positiva de creador de surcos en la tierra y recogedor de frutos, ensalza el compromiso continuado de la voz poética, y surge como una protesta contra la experiencia del exilio que al fin parece definir la identidad del propio escritor, y de su posible imagen personal como fracaso político. Las descripciones del paisaje campestre se convierten en metáforas directas de su exilio, en las que el poeta que se transforma en agricultor y sembrador cumple la función social política de alertar a sus conciudadanos, al mismo tiempo que contribuye a producir resultados diferentes a los que han provocado su situación material:

\footnotetext{
Porque si no es esta mi tarea,

ni mi senda trazada;

si no preparo los campos

para la siembra de mis versos;

si no lucho por ser luz,
}

\footnotetext{
La importancia del espacio geográfico perdido es inestimable en la experiencia del exilio. Tal como lo vivió Edward Said: "Exile is predicated on the existence of, love for, and a real bond with, one's native place; the universal truth of exile is not that one has lost that love or home, but that inherent in each is an unexpected, unwelcome loss" (xv).
}

Revista Iberoamericana, Vol. LXXX, Núms. 248-249, Julio-Diciembre 2014, 813-833 


\author{
y, por la luz, elimine \\ de las mentes las tinieblas; \\ si no alzo mi voz en versos \\ claros que pregonen \\ el mensaje de la paz \\ y la reconciliación, \\ ¿de qué me sirve ser poeta? (Requiebros 53)
}

En esta copla IV de "La siembra" se ve al autor exiliado presente en el paisaje y en elementos del mundo natural (senda, campos, luz, tinieblas) hasta el punto de que su identidad se define por este mundo. Metafórica y literalmente, el poeta se siente extraño y aislado, un cautivo de las tinieblas, por lo que desdobla su proceso de identificación (con el pasado y el presente), para buscar consuelo en la naturaleza, a veces ajena a él. En estos casos, tormentas, oscuridad, sequía son elementos naturales que funcionan como espejo de la agonía experimentada por el poeta. Sin poder olvidar su expulsión, el paisaje invocado parece que también se haya exiliado como consecuencia de que la libertad "fue apenas una pompa de jabón/ pretendiendo flotar/ incólume entre briznas/ de paja y arena, movidas/ por la tormenta/ de una noche tropical" ("Elegía", Requiebros 33). Estos poemas reflejan y responden a la hostilidad del medio ambiente real en que el poeta vive, facilitando que su propio sentido de alienación pueda sentirse atenuado en el proceso de reflexión y comparación que la naturaleza le provee.

Las manifestaciones de nostalgia, o requiebros, por el paraíso guineano perdido constituyen por tanto un modo de exploración y compensación de la realidad exílica, enriqueciendo, ampliando su significado. Tal como indica Noel Valis las dos nociones, nostalgia y exilio, tienen características diferentes al mismo tiempo que son interdependientes: "Nostalgia originally meant 'homesicknes,' only later becoming identified with vague feelings of longing. Exile (exsilium) was banishment, expulsion from one's home and was later extended metaphorically to the very place of exile" (117). El exilio produce transformaciones materiales, palpables como el desplazamiento y el desarraigo físico, mientras que la nostalgia es una de las estructuras de sentimientos producidas por la condición exílica. En el caso de Balboa Boneke, las expresiones de melancolía y añoranza (como el poema con ese título de Requiebros 15) constituyen a veces muestras convencionales de nostalgia superando, sin embargo, los sentimientos de angustia, rechazo, nihilismo y autoaniquilación que aparecen en otros escritores exilícos (Bevan 28). Sus versos revelan sobre todo una visión productiva, positiva y vehemente sobre la necesidad de asumir esa realidad y superarla, tanto a nivel personal como colectivo. De modo similar a lo que observa Munro en la obra del escritor haitiano Emile Ollivier, Passages, la experiencia del exilio trae consigo un sentimiento de identidad dispersa, lo que provoca un movimiento doble en el que la alienación y la separación física personales pueden interpretarse como una vivencia colectiva, en la

Revista Iberoamericana, Vol. LXXX, Núms. 248-249, Julio-Diciembre 2014, 813-833 
que el sujeto se vacía de su identidad social al mismo tiempo que invierte en ella al dar nuevos significados a su proceso de exilio; "a new personalized and yet also collectivized concept of Haitianness" (35). Los poemas de Balboa Boneke se constituyen como un intenso y complejo proceso de reflexión personal y social que facilita la re-construcción de la filiación del sujeto guineoecuatoriano con la patria, situada a miles de kilómetros de distancia. Transcendiendo el ámbito de la escritura como expresión de la nostalgia y/o reflejo de lo personal, estas composiciones manifiestan las coordenadas identitarias de la comunidad exiliada, adquiriendo un significado político.

Muestras del compromiso político de Balboa Boneke son las referencias que hace al "Futuro" (Requiebros 19), a las "Quimeras" (Requiebros 41-42), al reclamo por una Guinea mejor ("A Nosotros los exiliados" Requiebros 60-1), a la fe en la paz ("Acto de Fe I" Sueños 23-4), y a la posibilidad de que "Así, juntos y hermanados,/ retornaremos a la amada tierra/y enriqueceremos/ nuestro fértil jardín ecuatorial" ("La amistad", Sueños 53), mostrando que el poeta cree en la posibilidad de desexiliar el exilio y de construir una patria alternativa. A pesar de que el sujeto haya sido expulsado de su país, y por lo tanto de su historia, el yo poético se presenta decidido a inscribirse en la memoria colectiva y a retar la clave que explica su experiencia traumática. El hecho de que confronte la violencia que ha sido infligida sobre él, y ofrezca una postura conciliatoria entre todos los exiliados, aspirando a una visión idealista en la que los conceptos abstractos de paz, libertad, y futuro adquieren una dimensión inmediata y contumaz, tiene un sentido que es político. Por ejemplo, la última estrofa de "A nosotros los exiliados" indica sin lugar a dudas este sólido empeño:

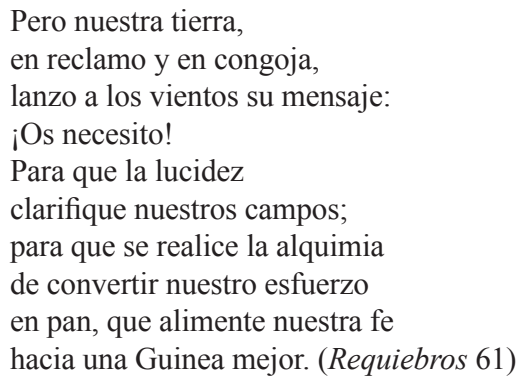

La salida abrupta o condicionada, el imposible retorno, la transformación de los exiliados en los enemigos del poder de turno, la soledad y agotamiento del destierro se convierten en la obra de Balboa Boneke en temas de agitación colectiva con consecuencias nacionales más allá del final de los gobiernos autoritarios y del exilio como acontecimiento histórico. La conjunción del pasado y el presente, de la distancia y la presencia reavivan el acto de escribir y sus metas. Es en este sentido que la escritura 
adquiere un valor patriótico, porque revela la encrucijada personal del autor exiliado que escribe las historias de dos espacios, dos tiempos, dos universos simbólicos y existenciales, uniéndolas de modo indeleble. Así la relación usualmente antinómica entre lo real y el discurso revienta, y fomenta el diálogo de la escritura del exilio con la realidad inmediata. El exilio adquiere de nuevo su conexión con una realidad social y nacional insoslayable, examinando condiciones específicas del sujeto africano. Este tipo de obra entra en contraste con un abundante número de escritos contemporáneos en los que, como indica Naficy, recientemente el concepto de exilio ha sido redefinido "from a strictly political expulsion and banishment to a more nuanced, culturally driven displacement" (9), fomentado por conceptualizaciones postmodernas de globalización, medios de comunicación, y desplazamiento de personas y capital. Frente al exilio visto positivamente como una opción personal más que una necesidad social, en el caso que nos ocupa, "exile must not be thought of as a generalized condition of alienation and difference, or as one of the items on the diversity-chic menu. All displaced people do not experience exile equally or uniformly. Exile discourse thrives on detail, specificity, and locality. There is a there there in exile" (Naficy 4). ${ }^{6}$ Es decir, en la obra de Balboa Boneke el concepto de exilio exige implícita y explícitamente una patria ausente y presente, Guinea Ecuatorial, con un espacio físico y mental de pertenencia como referente material y punto de destino final. ${ }^{7} \mathrm{Y}$ estos puntos de referencia son fundamentales para todos: el hablante poético, el propio escritor exiliado y la comunidad guineoecuatoriana que los poemas pueden representar.

\section{RE-ENCUENTRO CON LAS RAícES y VISIONES ALTER-NATIVAS DE GUINEA ECUATORIAL}

Mientras que el exilio físico es extremadamente doloroso, el exilio espiritual parece ser aún más destrozador, exigiendo el retorno del sujeto a sus orígenes para purificar su

6 Malkki afirma por ejemplo que "Exile is a central theme in twentieth-century literature" (513). Los conceptos de exilio y diáspora han ganado popularidad en varios ámbitos en el sentido de ser idealizados y romantizados como un modo de ganar poder y libertad creadoras, a pesar de tener consecuencias negativas como la deshistorización y depolitización (514).

7 De modo similar, Mustapha Hamil es muy crítico sobre la visión postcolonial y postmoderna en la que el exilio parece observarse de un modo positivo, a veces incluso necesario, porque "rejection of the metahysical rhetoric of origin liberates the self from the bounded definition of identity, homeland, and nationhood" (Certeau 53), facilitando el alejamiento de uno mismo de lugar de origen, su lengua nativa y su patria para crear "a third man, a postcolonial phoenix raising out of the ashes of colonial and postcolonial history" (59). El hogar se convierte en esta visión en un espacio inventado, que se sitúa en la conyuntura de la relación fracturada entre el pasado y el presente (55). De este modo la memoria y la relatividad adquieren una importancia fundamental al modo imaginado por De Certeau en el que "Like those birds that lay eggs only in other species' nests, memory produces in a place that does not belong to it" (56).

Revista Iberoamericana, Vol. LXXX, Núms. 248-249, Julio-Diciembre 2014, 813-833 ISSN 0034-9631 (Impreso) ISSN 2154-4794 (Electrónico) 
alma y promover la acción social inmediata. ${ }^{8}$ Para Balboa Boneke esas raíces culturales son afro-hispanas, con referencias frecuentes a la tradición bantú. ${ }^{9}$ Como afirma él mismo, "más de una década alejado de mis raíces han hecho de mí un híbrido que ha de replantearse todo desde el principio [...] Desde España, ya en el exilio, me descubrí a mí mismo como bohobé (bubi), como guineoecuatoriano y como africano; todo ello como hombre de proyección universal" (N'gom, Diálogos 92-3). Esta recuperación e identificación con la herencia africana surge en la poesía de Balboa Boneke con dos acepciones diferentes: primero, como un viaje espiritual a las fuentes africanas para reafirmar raíces, y segundo, para presentar una crítica a los excesos producidos por la lectura radical que los gobiernos de Macías y Obiang Nguema hicieron de las culturas nativas de Guinea Ecuatorial, renovando lazos con la cultura africana con un afán liberador.

Es en muchas creaciones exílicas de los primeros años donde se encuentra, tanto en la obra de Balboa Boneke como de otros escritores guineoecuatorianos, un proceso de recuperación de lo que en 1958 Kwame Nkrumah denominó "la personalidad africana" (Young 245). Si bien la expresión de "personalidad africana" fue originalmente acuñada por el intelectual jamaicano Edwarí Blyden como la aserción de algo distintivo que estaba siendo alienado, en su relectura por el líder de la independencia ganesa la frase adquirió un significado político al referirse a aquellos sujetos que fueron forzosamente exiliados del suelo africano como esclavos primero, y de su herencia socio-cultural por los colonizadores europeos después, lo que motivó a que se buscaran prácticas culturales indígenas que debían ser recuperadas, liberadas de su condición de subalternidad (Mphalele 37).

Las referencias a los lugares de culto ancestrales, a la jungla, la sabana y a los rituales africanos, frecuentes en los poemas de Balboa Boneke, aspiran a reflejar el modo emocional y espiritual indígenas africanos. La experiencia del exilio que presenta la mediación entre dos culturas y dos espacios, reivindica con pasión ese mundo originario africano, precisamente por el sentimiento de alienación que se ha acentuado por su pérdida. Las estrofas segunda y quinta del poema "Salutación", con expresiones como "Te saludo, eco lejano de timbales/ que pregonas negritud/ y extirpe bantuguineana, te saludo./ Te saludo, sol tropical, te saludo brisa ecuatoguineana. ¡Oh, campos de dulce canto y sabor

8 La expresión de exilio espiritual, o pródigo (relacionado con el sentimiento de vulnerabilidad que produce) fue propuesto para hablar de esta realidad africana por Kofir Awoonor de Ghana y Christopher Okigbo de Nigeria . Este tipo de exilio se refiere a "according to Awoonor, exiles who abandoned our traditional shrines, leaving our fences to the termites, and dunghills to heap up in on our birthplace" (Mphahlele 38).

9 Véanse las entrevistas y varias composiciones en las que afirma ser afro-hispano. De hecho, esta definición es indicadora de la identificación dominante entre los escritores guineoecuatorianos hasta época reciente. Así, Donato Ndongo en la introducción a su antología literaria de 1984 afirma que "Guinea Ecuatorial está habitada por africanos cuyo idioma común es el castellano o español. [...] Las manifestaciones literarias de Guinea Ecuatorial (tienen) elementos primordiales: la africanidad [...] y el hispanismo" (11).

Revista Iberoamericana, Vol. LXXX, Núms. 248-249, Julio-Diciembre 2014, 813-833 ISSN 0034-9631 (Impreso) 
de africanidad, yo os saludo!" (Sueños 45) indican el uso de imágenes y escenas africanas que se proponen asiduamente en contraposición a las experiencias nuevas del contexto existencial del exiliado, con frecuencia en el territorio de la antigua colonia (en este caso Palma de Mallorca). ${ }^{10}$ Los conceptos de africanidad, negritud y la estirpe bantú se erigen como puntos de referencia identitaria nativista, coincidiendo con movimientos africanos similares, especialmente el del "Comité de Defense de la Race Negre", liderado entre otros por Leopold Senghor, que buscaron la rehabilitación de la "raza negra" a través del lenguaje, deconstruyendo los procesos de dominio fomentados por discursos coloniales (Young 260). A pesar de las diferencias históricas, el giro intelectual y las expresiones de los poemas de Balboa Boneke son muy similares a los del movimiento de "Negritude", de modo que la comparación puede considerarse todavía válida. Como indica Ndongo, la teleología de la Negritud fue la potenciación de Africa en el mundo, bien a través de mantener las lenguas africanas, ciertos motivos temáticos, o cosmogonías de este continente ("El marco" 52). Más allá de la lectura reduccionista reciente que critica cómo la ideología de la Negritud fue llevada a la práctica por sus líderes, u ofreció una visión limitada, aquí se propone prestar atención al impulso intelectual principal de dignificación y alabanza de África, y a los efectos pro-activos que tal movimiento tuvo a largo plazo, visibles aún en la actualidad. En los poemas de Balboa Boneke, aunque el contexto histórico es diferente (no son escritos en la época colonial o inmediatamente postcolonial), el movimiento intelectual es similar debido al desgarro del sujeto de su identidad material y espiritual. Como comenta Lahens al estudiar a escrito Edouard Glissant, una de las primeras reacciones del exilio, cuando no se está seguro de poder mantener el sistema de valores al que el sujeto se ha afiliado antes de salir, es manejar el concepto del retorno, lo que exige constituir una memoria y reafirmar las raíces que le conectan con el origen, de modo que proporcionen continuidad y elementos en común a la comunidad de pertenencia (736). De este modo, la pérdida de la vida comunal y las historias culturales compartidas, fenómenos provocados por el desplazamiento exílico, se reúnen en lo que Azade Seyhan denomina "memoria cultural”, a través de un trabajo restaurador que provee significado, propósito e integridad al pasado. La recuperación de la memoria cultural consiste por lo tanto en "an intentional remembering through actual records and experiences or symbolic interpretations thereof by any community that shares a common 'culture.' This culture could be linguistic, religious, institutional, migrant, diasporic, ethnic, or some combination of these" (Seyhan 15). El acto de recordar exige dar coherencia e integridad a la historia interrumpida por el proceso de pérdida. Por eso, la historia es vista no solamente como fue vivida por los actores o

${ }^{10}$ Entre los escritores africanos exiliados se observan referencias persistentes a la importancia de la localización espacial para definir la identidad cultural del sujeto, tal como indica Lovesey al analizar la obra de Ngugi wa Thiongo.

Revista Iberoamericana, Vol. LXXX, Núms. 248-249, Julio-Diciembre 2014, 813-833 ISSN 0034-9631 (Impreso)

ISSN 2154-4794 (Electrónico) 
víctimas de ella, sino que también es reelaborada por los narradores o contadores de la historia. ${ }^{11}$ Esto significa con frecuencia que escritores como Balboa Boneke van a ofrecer historias alternativas a la oficial, a reexaminar aspectos olvidados y ocultos, y con ello básicamente ofrecerán una reconexión de la vida presente - del autor y el lector-con la historia pasada -ahora revivida-. En este sentido los poemas históricos que a veces presenta aparecen como un documento social que resiste "the erasure of geographical, historial, and cultural differences" (Seyhan 7).

De modo similar, una posible interpretación del entusiasmo de Balboa Boneke por el mundo natural que aparece con frecuencia en sus poemas es que constituye una manifestación de su conciencia cósmica profunda, un sentimiento que tiene una cualidad casi religiosa y raíces africanas, y que es común a otros escritores del continente. Como afirma Donato Ndongo, "[D]esde la cosmogonía animista los espectros, los seres espiritualizados, las fuerzas invisibles son omnipresentes y dominan sobre esa naturaleza aparente" (Antología 17). ${ }^{12}$

Ahora, si el retorno a África requiere redescubrir el yo africano indígena, pero es difícil buscar una cultura africana pura y un encuentro equilibrado con la cultura del colonizador, en el caso de Guinea Ecuatorial un elemento problemático de la construcción de memoria es el mito de la unidad bantú, ya que ha sido movilizado por escritores y políticos produciendo resultados opuestos en la visión de la nación: idealista de unión de varios grupos o nativista restrictivo tal como fue impuesta por gobiernos nguemistas. Por ejemplo, el poema de Balboa Boneke "Unidad Bantú" afirma:

No me importa saber

si se aprecian o no mis poemas, ni que yo, hombre y poeta, soy mortal; pero sí me importa que tu y yo

11 Una aproximación similar la presenta M'bare N'gom quien habla de la memoria declarativa de Balboa Boneke para "proceder a la de-construcción de la memoria impuesta por el discurso nguemista" ("Memoria" 106).

12 Esta visión animista de la naturaleza ocupa un lugar privilegiado en la cultura bantú, transmitida además de por los escritores, por los estudios de Placide Tempels y Alexis Kagame, quienes ofrecen aproximaciones muy diferentes. Es importante señalar que a pesar de la posición crítica hacia la etnofilosofía, tal como la practicaba Placide Temples en aras de su misión de conversor al cristianismo, según el crítico africano Valentin Mudimbe, su libro Bantu Philosophy (1945), todavía escribía sobre este grupo de un modo respetuoso de modo que promovía "the concept of African theodicy or sign of a natural religion" (172). Por otro lado, los libros de Alexis Kagame, La PhilosophieBantu-Rwandaisede l'Etre (1956) y La Philosophie Bantu Compareé (1976), ofrecen una clara discontinuidad de pensamiento, en términos de Mudimbe, al presentar análisis desde el punto de vista lingüístico. Sin embargo, los dos escritores y sus seguidores coinciden en el hecho de que para ellos, "the affirmation and promotion of African philosophy meant a claim for an original alterity", es decir, de modos diferentes de los europeos de entender el mundo, o una gnosis distintiva (Mudimbe 45; mi traducción).

Revista Iberoamericana, Vol. LXXX, Núms. 248-249, Julio-Diciembre 2014, 813-833 ISSN 0034-9631 (Impreso) ISSN 2154-4794 (Electrónico) 
compartamos algo en común:

el espíritu y el alma africana y bantú. (Sueños 38)

Trascendiendo la experiencia e historia individual, el yo lírico proclama la aspiración a compartir "el espíritu y el alma africana y bantú" con su lector, probablemente buscando en su audiencia a sus compatriotas. Esta frase enfatiza la dignificación y resignificación que lo africano tiene para el sujeto exiliado, y representa un campo temático amplio que podría denominarse "obsesión con la integridad cultural", tanto a nivel político como literario, y que en otras literaturas africanas ha sido calificado de "nacionalismo cultural". El propósito de estas creaciones artísticas es retornar a una historia en la que se ve una agencia histórica positiva del sujeto africano, o en su carencia, en la que se exponen los contextos físicos y psíquicos que motivaron el exilio, y que se buscan superar. Es en este contexto en el que podría inscribirse la mayoría de la obra de Balboa Boneke. Poemas como "Cazador ecuatoguineano", que apela a múltiples grupos étnicos del país (bubi, fang, annobonés, ndowé, bishió) y "Mi gran sueño" que invoca la unidad de toda África y afirma la necesidad de alimentar "mi alma guineana y bantú" (Literatura 248, 255-6), muestran este acercamiento a una construcción nacional que se opone a las imágenes impuestas por las dictaduras nguemistas o a las heredadas de la colonización española. ${ }^{13}$

Aquí es necesario recordar con Young que un tratamiento analítico del nacionalismo en África muestra que los proyectos nacionalistas son muy recientes en este continente y revelan los legados de las naciones colonizadoras. Sin embargo, el sentimiento nacional se popularizó y arraigó lo suficiente para alimentar movimientos de liberación nacional a partir de los años 50 y triunfar con los procesos de independencia. Este tipo de alianza adquirió de nuevo relevancia con el fracaso generalizado de las nacionesestado africanas en los años 70 y 80 . Una característica dominante es, según Young, la persistencia y capacidad que el sistema estatal africano tiene para sobrevivir incluso en grandes crisis y situaciones de colapso (15). De modo similar Kwame A. Appiah señala que los intelectuales africanos no creen en el concepto de autodeterminación nacional por el hecho de que el nacionalismo moderno constituya parte del legado colonial, o una herramienta de dominio neocolonial, sino que mas allá de estas posibilidades,

the idea of the nation provided-first for the local elite, then for the newly proletarianized denizens of the colonial city, and finally even for a peasantry attempting to come to terms with its increasing incorporation into the world system-a way to articulate a resistance both to the material domination of the world empires and to the more

13 La empresa colonizadora sometió al sujeto colonizado africano a procesos de racialización y territorialización o partición arbitraria de sus territorios. Como resultado surgieron dos modos de nacionalismo: el panafricanismo o nacionalismo continental, y la expresión nacionalista tradicional que requería la liberación territorial inmediata.

Revista Iberoamericana, Vol. LXXX, Núms. 248-249, Julio-Diciembre 2014, 813-833 
nebulous threat to precolonial modes of thought represented by the Western project of cultural ascendancy. (53-4)

En concordancia con este paradigma general, el escritor guineoecuatoriano Justo Bolekia Boleká explica que:

Como la mayoría de los gobiernos de los Estados de África, Guinea Ecuatorial es un país artificial y ficticio que ha sido creado por los caprichos de la historia. Ningún guineoecuatoriano fue consultado para constituir su actual Estado. Por eso, hoy para garantizar la convivencia entre los distintos Pueblos que conforman este Estado, se ha de promover un modelo de Estado en el que se defienda la diversidad etnocultural e histórica de cada una de las etnias ámbö, bubi, fang y ndowé. (151-52)

En este contexto, la unión de los pueblos africanos y bantús propuesta por Balboa Boneke es un camino de construcción nacional. ${ }^{14} \mathrm{Y}$ la elaboración de un imaginario común como base de una identidad nacional unificadora ("compartamos algo en común", dice el poema) supone una respuesta positiva y un avance considerable a la destrucción acarreada por el exilio.

Sin embargo, este mismo impulso unificador aludido en conceptos y expresiones como "unidad bantú" ha sido manipulado y reforzado por las dictaduras Nguemistas al imponer una interpretación restrictiva para justificar su brutalidad. Como indican los títulos de múltiples poemas: "Vencedores y vencidos", "El regreso", "Largo camino", "Alegría en mi alma (final de un exilio)", "Tres de agosto 1979", "Renacimiento (Malabo)", "En busca de luz y cordura" y "Paloma ecuatoguineana-paloma extraviada" la historia nacional fue secuestrada por el nguemismo. En palabras de M'bare N'gom, “el discurso africanizante en Guinea Ecuatorial se transformó en un proyecto 'monoétnico'. Francisco Macías Nguema se escudó tras un supuesto nacionalismo anticolonial y antineocolonialista para suprimir cualquier forma de oposición política y monopolizar la representación nacional" ("Memoria” 103). Más concretamente como explica George Cusack todos los grupos étnicos de este país hablan lenguas bantús y se consideran bantú culturalmente, pero "el mito de la unidad bantú" que une a todos los grupos de Guinea Ecuatorial "to a journey from 'the holy land' to their present location" ha sido manejado para establecer el dominio absoluto del clan Essangui (78-9). Coincidiendo con esta evaluación Bolekia Boleká estima que,

En los más de treinta y cuatro años de dictaduras nguemistas se han activado los campos del odio y la desconfianza, del dolor y la desilusión, del ombligo y el ensimismamiento

14 Como señala Cusack "Bantu unity is also linked to the idea of African unity and the Pan African movement" aspectos enfatizados por escritores guineoecuatorianos (79).

Revista Iberoamericana, Vol. LXXX, Núms. 248-249, Julio-Diciembre 2014, 813-833 ISSN 0034-9631 (Impreso)

ISSN 2154-4794 (Electrónico) 
étnico frente a la impotencia e indefensión ante la barbarie de los alienantes gobernantes cleptócratas y tribalistas, para quienes el Estado carece de cualquier sentido extrafamiliar. La falta de arraigo de la Soberanía general, asentada sobre una eficaz burocracia gubernamental protegida, a su vez, por una estratificación social, todo ello dentro de una cultura dominante, frena cualquier proyecto de estado. (153)

Aunque el grupo Essangui solamente representaba un 1.5\% de la población nacional en el momento de la independencia y se localizaba en el distrito de Mongomo (en la zona más oriental del territorio continental) Macías transformó la presidencia del país en un gobierno personalizado de modo que "the dictatorship was not so much a triumph of Fang nationalism as it was a triumph of the president's hometown coterie" (Sundiata 66). Con los gobiernos de Macías y Obiang, el mito de la unidad bantú insiste en minimizar diferencias entre todos los grupos étnicos del territorio nacional para evitar impulsos separatistas por los bubi (Cusack 84), y facilitar el control férreo del grupo dominante:

The current governing elite, bolstered by the international community in various guises, is likely to continue to build an Equatoguinean identity using such resources as myths of 'Bantu unity' [...] The idea of a 'Bantu unity,' which emerges in the discussions on art and Spanish-language literature of Equatorial Guinea, is not 'innocent': the protagonists are often those who have co-operated with the second Nguemist regime and whose personal future, and the ability to profit financially from the state, depends on the acceptance of the existing union of Rio Muni and Bioko. ("Nation-builders" 93)

Otra expresión utilizada para denominar el control nguemista de Guinea Ecuatorial, indicando conexiones con otras partes del mundo hispano, es la de "caudillismo familiar", aunque según Geoffrey Wood, "Nguemist regime matches or exceeds earlier Latin American manifestations both in rapacity and brutality; President Obiang Nguema Mbasago is regularly named as one of the worst despots in the world" (547). La historia reciente de corrupción política se manifiesta en la celebración de elecciones fraudulentas en 1996 y 2002, con un apoyo triunfal sospechoso del 97\% de la población. Estos resultados son obtenidos en un ambiente de inflación de la población nacional (de 500.000 habitantes a un millón), voto no secreto, y uso de violencia y represión contra los candidatos de oposición. A pesar de la existencia de numerosos partidos de oposición que se han legalizado o no, dentro y fuera de Guinea Ecuatorial, el poder político y económico se halla altamente restringido al clan familiar del presidente, procedente de Mongomo, "[A]lmost all members of the armed forces, which secure and interpenetrate the family elite, are recruited here. Real authority resides in both the hometown and the sprawling presidential area in Malabo (Wood 549-50).

Frente a la "clanización" de los Esangui, los poemas de Balboa Boneke encajan con el modelo de identidad ofrecido por ciertas obras autobiográficas del exilio en las que el protagonista intenta constituir un sujeto coherente, a nivel personal y

Revista Iberoamericana, Vol. LXXX, Núms. 248-249, Julio-Diciembre 2014, 813-833 ISSN 0034-9631 (Impreso)

ISSN 2154-4794 (Electrónico) 
nacional (Mardorossian 24). El yo lírico presenta un sincretismo de valores hispanos y africanos, e insiste en reanimar las raíces africanas para unir liberadoramente a todos los guineoecuatorianos. El mito de la unidad bantú se rearticula positivamente, y aunque existen dudas sobre su veracidad (Cusack 79), Balboa Boneke muestra que, como afirma Stuart Hall, más importante que el pasado, o lo que se denomina "la arqueología de la identidad", lo que adquiere relieve es la "producción de la identidad". El significante "bantú" se presta por lo tanto a lecturas opuestas dependiendo del modo en que el gobierno y Balboa Boneke lo articulan. En sus poemas, más allá de su realidad histórica el concepto de unión bantú acentúa el mismo proceso de unificación de los pueblos de Guinea Ecuatorial que Obiang le da, pero en dirección contraria. Balboa Boneke es altamente cauteloso al interpretar el poder unificador de este adjetivo, buscando una lectura liberadora, que supere los conflictos interétnicos que según él afectan a la sociedad guineoecuatoriana. Así, en un ensayo reciente afirma refiriéndose al modelo nguemista que, "[L]os nacionalismos dogmáticos, exacerbados y excluyentes, pertenecen a un mundo arcaico hoy desfasado, propio de archivos históricos" ("nos conviene"). Como respuesta, el escritor aserta la necesidad de reivindicar sus derechos étnicos como bubi, promoviendo un sentido de unidad en la diversidad.

Según Balboa Boneke "para la destrucción de la dictadura que dura ya treinta años, NOS CONVIENE CERRAR FILAS en torno a una idea común". De este modo, la narración personal y social que se construyen en los poemas de Balboa Boneke sobre el "pueblo bantú" dialoga con su visión opuesta, y por tanto avanza la posibilidad de modificar la historia política y social real (Erens 45). Ciertamente, para conseguir tales logros es necesario prestar atención a varios elementos como la visibilidad de la obra de este autor, y con ello su capacidad de reclamar una audiencia que participe de sus metas, además de las posibilidades que una comunidad nacional en el exilio tiene para elaborar una visión de estado-nación que constituya una alternativa pragmática efectiva. En este sentido, el impacto de su obra puede verse restringido por la limitada esfera de circulación de la literatura de Guinea Ecuatorial, que se encuentra en el cruce de caminos de estudios hispánicos y estudios africanos, con los dos campos abriendo lentamente las puertas a estas manifestaciones culturales. Paralelamente, a pesar de que Balboa Boneke ha pasado más de 20 años viviendo en el exilio en España, y como indica Elisa Rizo "los intelectuales en el exilio son prácticamente excluidos del proceso (nacional), al ser considerados conceptualmente como 'intelectualidad de la oposición' (151), es interesante notar que incluso utilizando una actitud de confrontación el gobierno de Obiang toma nota de la actividad creadora de estos escritores (151-52). La oposición y exclusión activa nguemista tiene el efecto paradójico de valorarla, indicando por tanto el proceso de contestación nacional al que contribuyen los poemas de Balboa Boneke.

Además de la revaloración de fuentes comunes bantús, los escritos de Balboa Boneke producen una historia alternativa del país al denunciar y criticar la explotación

Revista Iberoamericana, Vol. LXXX, Núms. 248-249, Julio-Diciembre 2014, 813-833 ISSN 0034-9631 (Impreso) 
específica de los gobiernos de Macias y Obiang Nguema que han motivado el exilio. Así, el poema "Vencedores y vencidos" habla de un "glip, glop,/ goteo agónico,/ sangría lenta,/ década de angustia y dolor, expatriación, silencio de muerte, silencio,/ silencio y oscuridad"; revela el proceso de aniquilación que el régimen de Macías trajo. La destrucción y la impotencia fueron resultados crueles e inesperados de la primera presidencia democráticamente elegida en el país. Las expresiones elegíacas del mismo poema (vencedores y vencidos) que dicen “ $¡ O$ Oh, corazones doloridos!/¿dónde sepultar vuestra congoja?/ ante tanta ruindad/ en una década acumulada/ ante tanto exterminio y muerte fratricida,/ díme mujer, contéstame madre:/¿quién ganó y quién perdió?” se convierten en manifestaciones duras de la sorpresa y acritud generadas por la dictadura que destrozó a la nueva nación. En palabras de M’bare N'gom,

[D]esde la poltrona de esa "legalidad", la corrupción, el clientelismo, el "tribalismo", el nepotismo y la represión se convirtieron en doctrina de Estado. Guinea se convirtió en un gigantesco campo de concentración, una "gran Jaula", y el resultado inmediato fue un país enajenado, fragmentado y traumatizado. Durante casi once años, Guinea Ecuatorial, como espacio social, cultural y político y económico, fue secuestrado y silenciado. ("Introducción" 20)

Respondiendo a la desesperación, la poesía lírica y narraciones celebradoras del nacimiento de una nueva época, cantando el triunfo de la independencia, se transforman ahora rápidamente en duras descripciones de la agonía sentida por haber perdido el camino. Títulos de poemas como “¿Dónde están la cordura y la razón?”, "Frustración y esperanza", "Paloma ecuatoguineana-paloma extraviada" y "Otras voces en el silencio" (Sueños), muestran que el exilio es el resultado desgarrador de "el mundo de la gran esperanza y de la gran ilusión, el de la autodeterminación, pero, por la represión y los crímenes de Macías, esa esperanza y esa ilusión fueron tronchadas" (Porqué nos conviene). En este sentido, la experiencia del exilio guineoecuatoriano es comparable a casos similares en el continente africano que representan cómo los procesos de independencia postcolonial fueron extraviados por sus dirigentes. La literatura del exilio de Guinea Ecuatorial se sitúa pareja a obras como The Beautiful Ones Are not Born Yet, de Ayi Kwei Armah (Ghana), A Man of the People, de Chinua Achebe (que profetiza la guerra civil nigeriana) o Kongi's Harvest de Wole Soyinka que satiriza la figura del moderno dictador.

Sin embargo, el fin de esta dictadura que destrozó la vida de un tercio de la población del país, incluyendo 120,000 exiliados según las estimaciones del historiador Max Liniger-Goumaz, no trajo un cambio de ruta nacional (Historical Dictionary 95). A pesar de las perspectivas positivas que se exaltan en el poema "Tres de agosto 1979" que dice "al conjuro del TRES DE AGOSTO,/ que fue el undécimo año/ de tortura e iniquidad,/ surgió de pronto un destello/ que brotó de las tinieblas,/ y fue el principio

Revista Iberoamericana, Vol. LXXX, Núms. 248-249, Julio-Diciembre 2014, $813-833$ ISSN 0034-9631 (Impreso)

ISSN 2154-4794 (Electrónico) 
de otro despertar/ y raíz de renovada ilusión" la dominación nguemista continuó sin sentido (Sueños 48). El autoritarismo de los años 1980 a 1990 se convirtió para Balboa Boneke y otros intelectuales en la "década de la gran frustración", porque como le explica a M'bare N'gom,

todos mirábamos el futuro con esperanza, pero ahora, bajo el actual régimen, dudamos que haya futuro, pues los signos represivos del poder fáctico son sus elementos negativos: la gran corrupción, el nepotismo a ultranza, el endiosamiento del líder en el poder y demás vicios, sobre todo la represión en ocasiones cruenta, hacen de esa década, o han hecho de ella, la del vacío y de la frustración. (Diálogos 98)

Efectivamente aunque muchos de los profesionales e intelectuales que se hallaban exiliados regresaron a Guinea tras el llamado "golpe de libertad" con el propósito de participar en el proceso de reconstrucción y reconciliación nacionales, la mayoría de ellos tuvo que volver a salir para salvar sus vidas. Tal como recoge Liniger Goumaz, el líder de la oposición en el momento del triunfo de Obiang, Eya Ncham ya había previsto que "Sin una oposición cívica representativa, Obiang Nguema se convertiría en otro Macías Nguema" (Small 145). Sin duda, a pesar de que Obiang Nguema había apelado a la reconciliación nacional, él mismo había eliminado la participación de la mayoría de los políticos de la oposición, restringiendo todo tipo de derechos y libertades (Sundiata 82). N'gom explica este proceso sucintamente, “[P]or un lado, el discurso hegemónico-étnico nguemista se hizo apologético; y por el otro, surgió lo que se podría denominar la visión del silencio o de la subcultura, la cual, operando desde una situación de marginalidad, se constituyó en discurso alternativo e intentó describir, sobre todo desde el exilio, el trauma histórico y cultural que vivía Guinea Ecuatorial" ("Introducción" 21). Como consecuencia la visión exílica que domina en la obra de Balboa Boneke al reflexionar sobre esta segunda etapa nguemista es una de desesperación, en la que prevalece el nihilismo. ${ }^{15} \mathrm{Y}$ la desilusión se radicaliza por el modo en que la realidad política y social contrasta con las promesas abortadas de la post-independencia. ${ }^{16}$

${ }^{15}$ Como explica Milosz la desesperación es un sentimiento que usualmente aparece en la primera etapa del exilio. Hay tres causas principales que pueden producirla: la pérdida del nombre, el temor a fracasar y el tormento moral (282). En el caso de Balboa Boneke la imposiblidad de actuar o transformar su país causa este sentimiento.

${ }^{16}$ Una experiencia paralela es sufrida por Mphahlele, el escritor sudafricano que dice, "[A]lmost overnight after independence, I witnessed the tragic unfolding of the imperial theme, as Shakespeare would dramatize it. News filled the air of treachery, assassination, palace rebellions, preventive detention, corrupt government, neo-colonial plots to subvert independence, public executions involving rebels, of persons being liquidated by murder as members of the parliamentary opposition, and so on. Such news still hangs over the whole African landscape. Each time the bell tolls the death of one person, several refugees spill across borders" (30). Este sentimiento de desahucio vital es también comentado en detalle por Olowonmi (57).

Revista Iberoamericana, Vol. LXXX, Núms. 248-249, Julio-Diciembre 2014, 813-833 ISSN 0034-9631 (Impreso) ISSN 2154-4794 (Electrónico) 
Al final parece que lo único que le queda al artista africano en el exilio es, como afirma el poema "Déjame soñar, hermano", soñar con que la justicia y la paz, la libertad y la razón, se hagan algún día realidad. Por ello, y sin disminuir la carga de violencia, incertidumbre, provisionalidad, pérdida de referentes y fractura personal y política, acarreada por el exilio, los poemas de Balboa Boneke analizan también los diferentes guiones identitarios que unen la experiencia de la voz poética de su obra a la de otros compatriotas que interpelan la comunidad con la que se identifican (sea guineana o africana) desde diferentes posiciones sociales, políticas y geográficas. Así, la patria que se experimenta como hogar perdido, al que se ha abandonado en forma abrupta y no deseada, se convierte al mismo tiempo en un sustrato de procesos de identificación para aquellos que buscan una redistribución del poder en sus sociedades de origen. Las composiciones exílicas se convierten entonces en una búsqueda e interpretación de la comunidad nacional y la africana. La suya es una poesía que profundiza en el proceso de re-conocimiento de sí mismo y su país. Algunos de sus poemas como "Mi gran sueño" avanzan un proyecto de compromiso y conexión con otros ciudadanos africanos. Así, la invocación a Africa en "Mi gran sueño" muestra un espíritu panafricano que lograría dignificar y liberar a todos los habitantes del continente y sus descendientes "Anoche tuve un sueño:/ y con mi sueño e ilusión/ lanzo a los vientos mi grito de fe ¡Creo!/ Creo en la eternidad inexpresable,/ creo en la utilidad del verbo, creo en el silencio de la razón,/ creo en la Unidad del alma africana,/ y creo en ti. ¡CREO EN TI, ÁFRICA!" Otras expresiones panafricanistas se presentan en los poemas "Unidad bantú", "Sin fronteras", "Quiero ser vida y amor" (Sueños) y "Futuro" (Requiebros), y aluden a la historia específica de Guinea Ecuatorial, al mismo tiempo que la inscriben en el contexto continental.

Como indica Eugenio Nkogo Ondó, el filósofo y escritor guineoecuatoriano, el panamericanismo ofrecía en sus comienzos con líderes africanos y afro-americanos como Nkrumah, Padmore, Dubois y Sankara, la posibilidad de organizar a las fuerzas sociales africanas en una acción positiva que lleve a la justicia social, aboliendo la oligarquía para conducir al pueblo a la independencia de la explotación colonial (153). El fundamento de la nueva sociedad se establecerá de hecho sobre la sociedad tradicional que ya "gozaba de una auténtica organización democrática" (155). Este proyecto de un gobierno continental africano surgía en el diseño de Nkrumah como una vía socialista de unión para obtener la liberación del capitalismo y el neoliberalismo impuestos por poderes occidentales. Truncado de cuajo con el asesinato de su líder y la muerte de varios seguidores, el espíritu de sus propuestas sigue vivo. Para Nkogo Ondó, "[S] i Ghana fue la cuna del panafricanismo nkrumahista, hoy en día les toca a los demás países africanos esforzarse por la resurrección de su ESPÍRITU. Eso sería posible si fueran capaces de unir su independencia política a la económica, con el fin de construir una sociedad segura, justa e igualitaria" (160).

Revista Iberoamericana, Vol. LXXX, Núms. 248-249, Julio-Diciembre 2014, $813-833$ ISSN 0034-9631 (Impreso)

ISSN 2154-4794 (Electrónico) 
Inspirado por los sentimientos más ideales, especialmente el amor por su país, por la humanidad y por la familia(Lewis 42), la escritura de Balboa Boneke recrea sentimientos que cruzan el tiempo y muestran la lucha de re-situar el pasado, al mismo tiempo que parecen ser cruciales en el proceso de construcción de la identidad del poeta. Sus temas culturales, derivados de la experiencia personal tienen impacto nacional y continental e intentan reconciliar el pasado con el presente y un posible futuro. Su obra se convierte por tanto en un espacio cultural complejo que muestra la dialéctica de pertenecer (se) a sí mismo y a la nación, y lo opuesto, de perderse en los avatares políticos. En este sentido, Balboa Boneke muestra su compromiso político.

Como explica Mphahlele, el escritor sudafricano que vivió exiliado por más de 25 años, a pesar de que en el exilio el centro de la persona artista se siente herido, dañado, vulnerable, y la luz que debe ofrecer a sus conciudadanos se vuelve tenue y difícil de alimentar, en último término el escritor africano tiene que confrontar la condición mental exílica y resolverla, contribuyendo con su creación artística a la mejora de su sociedad. ${ }^{17}$ Esta visión comprometida con la sociedad de origen coincide con la interpretación del exilio africano que Nesbitt propone. Según él, el intelectual africano exiliado es obligado a enfrentarse al concepto de africanidad por primera vez cuando llega a vivir en un país occidentalizado, "[M]igrant African scholars must negotiate new identities that can no longer depend on the security of nationality and ethnicity but are not exactly African European or African American either. This dilemma of being-not exaclty African but not African European or African American-is the peculiar challenge of migrant African scholars" (71). Dependiendo del modo en que negocia su identidad, Nesbitt llega a distinguir tres tipos de intelectuales: "el comprador", el critico postcolonial y el exiliado progresivo, quien se compromete con la liberación de Africa, y a pesar de las tentaciones de participar en el sistema neoliberal, determina resolver el dilema de la doble conciencia propuesta por DuBois, a través del desarrollo de una identidad panafricana, al presentar un movimiento intelectual que va del marco local al continental africano.

Apuntando hacia una conclusión, como se ha observado en la obra de Balboa Boneke, la experiencia del exilio se conceptualiza con una carga histórica fortísima, asociando el proceso puntualmente a los regímenes autoritarios nguemistas. Muy específicamente su representación alude a la realidad que exige el manejo de visas y pasaportes porque hay fronteras físicas y políticas que limitan y condicionan la libertad del ciudadano guineano, al mismo tiempo que le desgarran de su país en la época fundamental de la

17 Okpewho explica que casi cada nación africana ha sufrido los abusos caprichosos de sus líderes como Modbut, Banda, Bokassa, Amin, Abacha. No se puede ignorar que la labor de los intelectuales africanos viviendo en el extranjero se halla siempre imbricada en preocupaciones políticas, siguiendo el modelo de intelectuales y activistas como DuBois, Padmore, James, Blyden y otros, que vieron la liberación de su raza (mi énfasis) como una obligación ética que no ve discontinuidad entre las metas intelectuales y políticas (71-72).

Revista Iberoamericana, Vol. LXXX, Núms. 248-249, Julio-Diciembre 2014, 813-833 ISSN 0034-9631 (Impreso)

ISSN 2154-4794 (Electrónico) 
independencia nacional. En este sentido, el exilio constituye la expulsión del individuo de su historia, colocando a los exiliados, en palabras de María Zambrano "al borde de la historia" (69). Y es precisamente la experiencia fundamental de este destierro la que da a esta expulsión simbólica y material un impulso político y social transcendentalmente africano. Esta representación del exilio es claramente distintiva de la que según la especialista Sophia McClennen se hizo popular a finales de los años 90, cuando bajo la influencia de filosofías de pensamiento post-estructuralistas y poscoloniales, el concepto de exilio se hizo popular como un medio o método de liberación del estado represivo de la identidad nacional, en el que el sujeto diaspórico y/o exílico vive una experiencia transnacional que puede ser liberadora, multicultural y creativa. Sin embargo, en el caso de Guinea Ecuatorial que nos ocupa, a más de 40 años de vista de la independencia, y considerando que buena parte de los intelectuales que representan la nación guineana han vivido en el exilio contra su deseo, la obra poética de Juan Balboa Bonek llama nuestra atención a la experiencia traumática que muchos guineoecuatorianos han vivido, al mismo tiempo que propone revivir la dimensión política de la actividad creativa en la formación de una memoria colectiva de Guinea Ecuatorial. Ahora, el reto para sus lectores y conciudadanos se constituye en estar atentos a cómo las interpretaciones de los exiliados se yuxtaponen y se suplementan con las de los intelectuales que han podido regresar y con las de aquellos que viven dentro de las fronteras nacionales.

\section{BibliOgRAFÍA}

Appiah, Kwame Anthony. In My Father's House. Africa in the Philosophy of Culture. New York: Oxford UP, 1992.

Balboa Boneque, Juan. Requiebros. Malabo: Centro Cultural Hispano-Guineano, 1994. Sueños en mi selva. Antología poética. Malabo: Centro Cultural HispanoGuineano, 1987.

O Boriba (el exiliado). Mataró: Agrupación Hispana de Escritores, 1982.

“¿Por qué nos conviene cerrar filas?” <http://www.angelfire.com/sk2/ guineaecuatorial/balboaboneke.htm $>16$ octubre 2008.

Bevan, David ed. Literature and exile. Amsterdam: Rodopi, 1990.

Bolekia Boleká, Justo. Aproximación a la historia de Guinea Ecuatorial. Salamanca: Amarú Ediciones, 2003.

Certeau, Michel de. The Practice of Everyday Life. Steven F. Rendal, trad. Berkeley: U of California P, 1984.

Cusack, Igor. "Nation-builders at Work: The Equatoguinean 'Myth' of Bantu Unity." Nationalism \& Ethnic Politics 47/3 (2001): 77-97.

Erens, Patricia Brett. "Crossing Borders: Time, Memory, and the Construction of Identity in Song of Exile." Cinema Journal 39/4 (2000): 43-59.

Revista Iberoamericana, Vol. LXXX, Núms. 248-249, Julio-Diciembre 2014, 813-833 ISSN 0034-9631 (Impreso)

ISSN 2154-4794 (Electrónico) 
Hamil, Mustapha. "Exile and Its Discontents: Malika Mokaddem's Forbidden Woman." Research in African Literatures 35/1 (2004): 52-65.

Lahens, Yanick. "Exile: Between Writing and Place.” Callaloo15/3 (1992): 735-46.

Lewis, Marvin A. An Introduction to the Literature of Equatorial Guinea. Between Colonialism and Dictatorship. Columbia: U of Missouri P, 2007.

Liniger-Goumaz, Max. Historical Dictionary of Equatorial Guinea. Metuchen: The Scarecrow Press, Inc. 1979.

Small is not Always Beautiful. London: Hurst, 1988.

Lovesey, Oliver "Ngugi Wa Thiong'o's Postnation: The Cultural Geographies of Colonial, Neocolonial, and Posnational Space.” Modern Fiction Studies 48/1 (2002): 139-68. Mardorossian, Carine M. "From Literature of Exile to Migrant Literature." Modern Language Studies 32/2 (2002): 15-33.

Malkki, Liisa H. 'Refugees and Exile: From 'Refugee Studies' to the National Order of Things.” Annual Review of Anthropology 24 (1995): 495-523.

McClennen, Sophia A. The Dialectics of Exile: Nation, Time, Language and Space in Hispanic Literatures. Purdue: Purdue UP, 2004.

Milosz, Czeslaw. "Notes on Exile." Books Abroad 50/2 (1976): 281-84.

Mphahlele, Es'Kia. “Africa in Exile.” Daedalus 111/2 (1982): 29-48.

Mudimbe, V.Y. “African Gnosis Philosophy and the Order of Knowledge:An Introduction” African Studies Review 28.2/3(1985):149-233.

Munro, Martin. "Unfinished Journeys: Exile, Africanity, and Intertextuality in Emile Ollivier's Passages.” Journal of Modern Literature 29/2 (2006): 33-49.

Naficy, Hamid. "Framing Exile: From Homeland to Homepage." Home, Exile, Homeland. Film, Media, and the Politics of Place. Hamid Naficy, ed. New York: Routledge, 1999. 1-13.

Ndongo Bidyogo, Donato y M'bare N'gom. Literatura de Guinea Ecuatorial (Antología).

Madrid: Casa de África, 2000.

Antología de la literatura guineana. Madrid: Editora Nacional, 1984.

"El marco de la literatura de Guinea Ecuatorial". Literatura de Guinea Ecuatorial (Antología). Donato Ndongo y M'bare N'gom, eds. Madrid: Casa de África, 2000. 31-57.

Nesbitt, F. Njubi. "African Intellectuals in the Belly of the Beast: Migration, Identity, and the Politics of Exile." African Issues 30/1 (2002): 70-75.

N'gom, M'bare. Diálogos con Guinea. Panorama de la literatura guineoecuatoriana de expresión castellana a través de sus protagonistas. Madrid: Labrys, 1996.

"Introducción". Literatura de Guinea Ecuatorial (Antología). Donato Ndongo y M'bare N'gom, eds. Madrid: Casa de África, 2000.11-29.

"Memoria y exilio en la literatura africana hispana". Palabras. Revista de la cultura y delas ideas. Fundación España Guinea Ecuatorial, noviembre 2009.97-110.

Revista Iberoamericana, Vol. LXXX, Núms. 248-249, Julio-Diciembre 2014, 813-833 ISSN 0034-9631 (Impreso)

ISSN 2154-4794 (Electrónico) 
Nkogo Ondó, Eugenio. “El panafricanismo ¿una respuesta a la globalización?” África, más cerca. El fin de un largo silencio. José Monleón, ed. Madrid: Entinema, 2008.

Okpewho, Isidore. "Home, Exile, and the Space in Between." Research in African Literatures 37/2 (2006): 68-73.

Olowonmi, Adekunle. "The Writer and the Quest for Democratic Governance in Nigeria: Transcending Post-Independence Disillusionment." The Journal of Pan African Studies 2/3 (2008): 55-67.

Rizo, Elisa. "La tradición en el teatro ecuatoguineano". Palabras. Revista de la cultura $y$ de las ideas. Fundación España Guinea Ecuatorial, noviembre 2009. 147-54.

Said, Edward. Culture and Imperialism. New York: Knopf, 1993.

Sampedro Vizcaya, Benita. "African Poetry in Spanish Exile: Seeking Refuge in the Metropolis.” Bulletin of Hispanic Studies 81 (2004): 200-14.

Seyhan, Azade. Writing Outside the Nation. Princeton: Princeton UP, 2001.

Shankar, Ravi and Jeffrey F.L. Partridge. "The Spirit of Exile. An Epistolary Essay." Journal of Postcolonial Writing 42/2 (2006): 129-138.

Sundiata, Ibrahim. Equatorial Guinea. Colonialism, State Terror, and the Search for Stability. Boulder: Westview Press, 1990.

Valis, Noel. "Nostalgia and exile." Journal of Spanish Cultural Studies 1/2 (200): 117-33.

Wood, Geoffrey. "Buisiness and Politics in a Criminal State: The Case of Equatorial Guinea." African Affairs 103/414 (2004): 547-67.

Young, Robert J.C. Postcolonialism. An Historical Introduction. Malden: Blackwell Publishing Ltd., 2001.

Zambrano, María. Carta sobre el exilio. París: Cuadernos, 1981.

Zeleza, Paul Tiyambe. "The Politics and Poetics of Exile: Edward Said in Africa." Research in African Literatures 36/3 (2005): 1-22. 
